\title{
Drug targeting in Acanthamoeba keratitis: rational of using drugs that are already approved for ocular use in non-keratitis indications
}

\author{
Abdul Mannan Baig ${ }^{1}$ \\ Received: 16 September 2018 / Accepted: 2 October 2018 / Published online: 24 October 2018 \\ (c) The Royal College of Ophthalmologists 2018
}

Acanthamoeba spp. is known to cause a sight-threatening Acanthamoeba keratitis (AK) and a usually fatal encephalitis called granulomatous amebic encephalitis (GAE). Though a successful prognosis of AK depends upon an early diagnosis, the availability of safer drugs to successfully treat AK remains a challenge. The rarity of AK has made the pharmaceutical industry reluctant to invest in the development of drugs against this vision threating keratitis. After AK was recognized as an orphan disease, a funded project, the Orphan Drug for AK (ODAK), the drug polyhexamethylene biguanide (PHMB) has been studied in Acanthamoeba polyphaga keratitis model [1]. There are reports that Acanthamoeba can persist causing an active infection despite treatment with chlorhexidine or PHMB [2]. Recent discoveries of cell surface receptors and druggable proteins in pathogenic variants of Acanthamoeba castellanii have revived the interest of repurposing of some anticholinergic drugs like atropine that are already used in non-infectious ocular disorders. The evidence of the presence of human-like muscarinic receptors in Acanthamoeba spp. [3], that are known targets of atropine, supports the possible forte of repurposing atropine and its structural analogs in AK. Furthermore, very convincing indications have come from retrospective studies where atropine was reported to treat cases of AK without the use of any concurrent anti-amebic agents [4, 5]. Since atropine is already given as an adjuvant drug in cases of AK, this novel action of atropine has the potential to make it the drug of choice in AK if large-scale human trials provide definitive results.

Atropine used in AK could have a clear superiority over the newer drugs as it is already known for its safety in the eye and is in use for diverse ocular indications. Atropine and

Abdul Mannan Baig

abdul.mannan@aku.edu

1 Department of Biological and Biomedical Sciences, Aga Khan University, Karachi, Pakistan analogs like dicyclomine and pirenzepine that have proven to be amoebicidal in Acanthamoeba castellanii in vitro [3] (Fig. 1) could also be investigated for their use in AK in an animal model of this disease. Dicyclomine and pirenzepine, of which the latter is a more specific muscarinic M1 receptor (mAChR1) antagonist, have proven to be more effective amoebicidal agents in doses lower than atropine in vitro studies [5] (Fig. 1d), but these drugs need to be evaluated for their ocular safety and efficacy in animal model and in human trials. Use of eye drops containing polyethylene glycol 400 $0.4 \%$ and propylene glycol $0.3 \%$ have also been reported to be amoebicidal and cysticidal. A decrease in the mitochondrial membrane potential and ATP levels were shown to induce chromatin condensation in Acanthamoeba spp. in a study showing the toxic effects of selected proprietary dry eye drops [6].

$\mathrm{AK}$, wound infection and GAE are notorious illnesses that are caused by Acanthamoeba spp., which are resistant to many anti-amebic drugs used at present. The prognosis of infections caused by this protist pathogen is very poor, which almost always results in blindness in AK (Fig. 2) and death in GAE. Development of new drugs is challenging and difficult as it takes a very long period to evaluate them for their safety and efficacies. Acetylcholine is known to stimulated the growth and proliferation of Acanthamoeba castellanii (Fig. 2a) [3] and anticholinergics like atropine, dicyclomine and pirenzepine antagonize strong proliferative signals generated from mAChR1 receptors (Fig. 2a) to exert an amoebicidal and cysticidal effects $[3,4]$. These drugs offer a unique opportunity to repurpose them for their utility in AK [5] which is known to be common in contact lens users (Fig. 2b). Anticholinergic approved by FDA and their synthetic structural analogs could be speedily brought to human trials and clinical utility in infections like AK and GAE caused by Acanthamoeba spp.

\section{Compliance with ethical standards}

Conflict of interest The author declares that he has no conflict of interest. The author has not received any assistance in writing this 

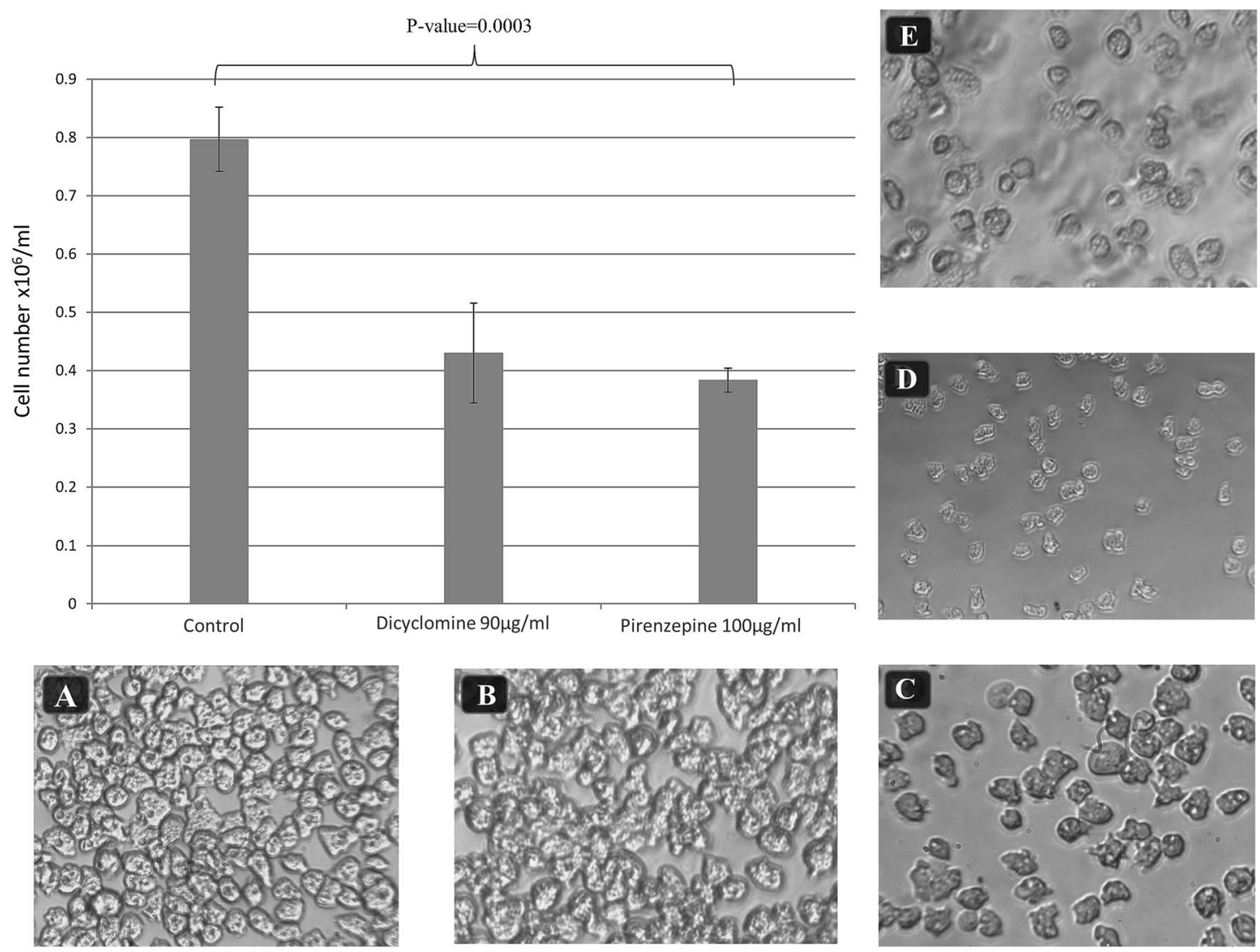

Fig. 1 A Histogram showing the results of muscarinic receptor antagonist drugs (pirenzepine $100 \mu \mathrm{g} / \mathrm{ml}$ and dicyclomine $90 \mu \mathrm{g} / \mathrm{ml}$ ) on $0.5 \times 10^{6}$ of the trophozoites of Acanthamoeba castellanii. Experiments were performed in triplicates. One-way Anova showed a $P$ value of 0.0003 . Dunnet's comparison test revealed a $P$-value $<0.01$ for - ve control vs dicyclomine $90 \mu \mathrm{g} / \mathrm{ml}$ and pirenzepine $100 \mu \mathrm{g} / \mathrm{ml}$.
Images show Acanthamoeba trophozoites in growth medium (a), solvent control (b), compared with $100 \mu \mathrm{g} / \mathrm{ml}$ of pirenzepine (c), dicyclomine (d), and $200 \mu \mathrm{g} / \mathrm{ml}$ of atropine (e), where the counts appear to be reduced, reflecting the anti-proliferative effects of these drugs in Acanthamoeba trophozoites 

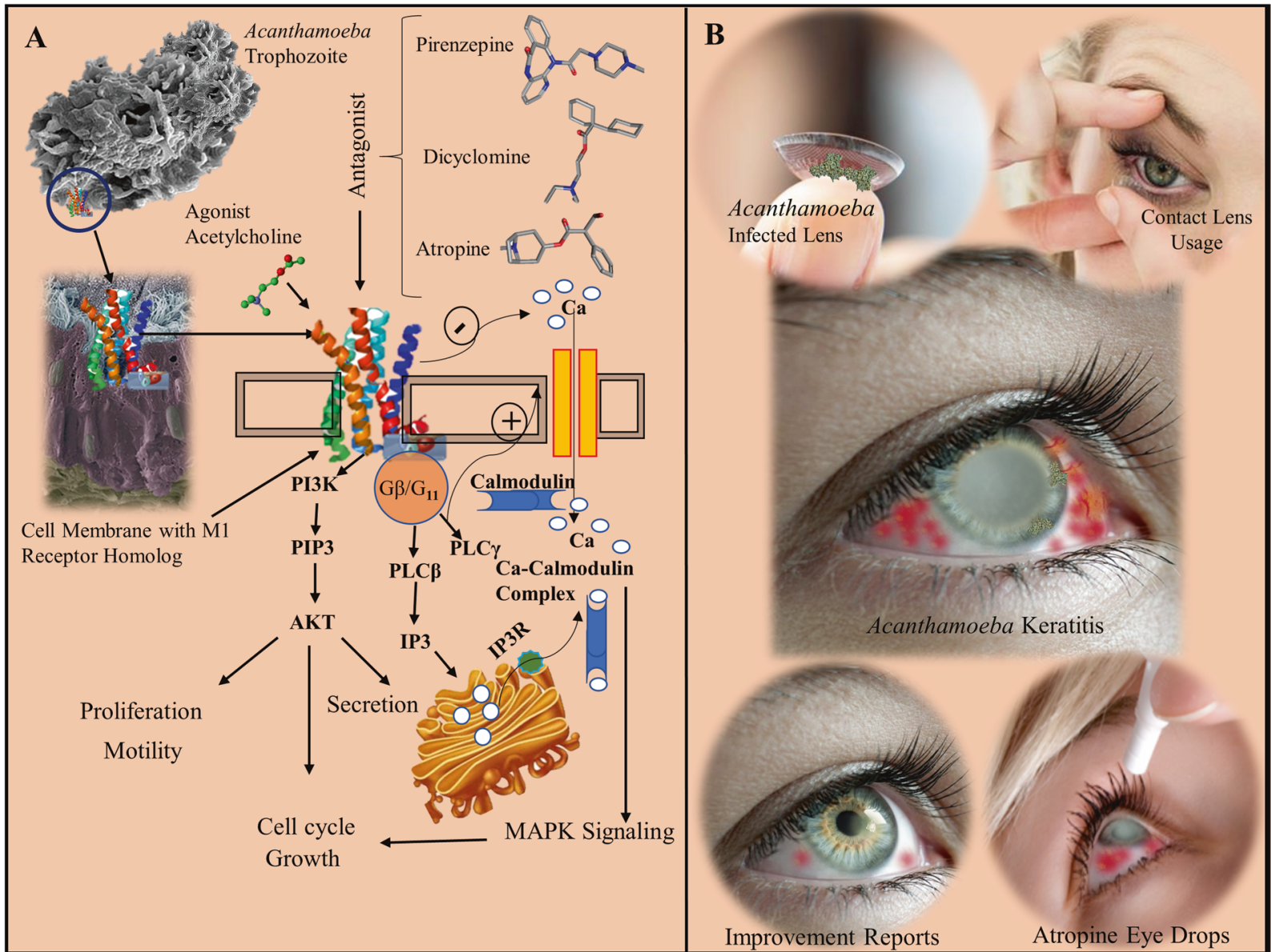

Fig. 2 a Schematic figure showing the effects of cholinergic agonist and antagonists in Acanthamoeba trophozoites. Muscarinic receptor stimulation has a growth promoting effect that results in proliferation in Acanthamoeba via calmodulin-AKT and calcium influx via voltagegated calcium channels. Antagonism of muscarinic like-homolog, the Acanthamoeba muscarine binding (AMB) receptor that has been recently reported in this protist pathogen by anticholinergic drugs (a)

paper and has no associations with the pharmaceutical companies. This project has been partly funded by Aga Khan University Pakistan.

\section{References}

1. Schlander Michael, Holm Søren, Nord Erik, Richardson Jeff, Garattini Silvio, Kolominsky-Rabas Peter, et al. 8th European Conference on Rare Diseases \& Orphan Products (ECRD 2016). Orphanet J Rare Dis. 2016;11(Suppl 1):1-9. https://doi.org/10. 1186/s13023-016-0515-y.

2. Seal DV. Acanthamoeba keratitis update-incidence, molecular epidemiology and new drugs for treatment. Eye (Lond). 2003;17:893-905. results in reduced proliferation and growth. b Shows sequence of events that follow the use of infected contact lens. Contaminated lens cleaning liquids are the most common source of infection that leads to Acanthamoeba keratitis (AK). Atropine used in the past has been reported to treat $\mathrm{AK}$ cases possibly by antagonizing the $\mathrm{AMB}$ receptor and its downstream pathways (a)

3. Baig AM, Ahmad HR. (2017). Evidence of a M1-Muscarinic GPCR homolog in unicellular eukaryotes: featuring Acanthamoeba spp bioinformatics 3D-modelling and experimentations. J Recept Signal Transduct Res. 2017;7:1-9.

4. Agahan AL, Lim RB, Valenton MJ. Successful treatment of Acanthamoeba keratitis without anti-amoebic agents. Ann Acad Med Singap. 2009;38:175-17.

5. Baig AM, Hareem Z, Khan NA. Recommendations for the management of Acanthamoeba keratitis. J Med Microbiol. 2014; https:// doi.org/10.1099/jmm.0.069237-0.

6. Sifaoui I, Reyes-Batlle M, López-Arencibia A, Chiboub O, Rodríguez-Martín $\mathrm{J}$, Rocha-Cabrera $\mathrm{P}$ et al. Toxic effects of selected proprietary dry eye drops on Acanthamoeba. Sci Rep. 2018;8:8520. https://doi.org/10.1038/s41598-018-26914-3. 


\title{
Comment on: Optimisation of intravitreal injection technique using a Barraquer speculum with solid flat blade and finger stabilisation
}

\author{
Salman Waqar ${ }^{1}$ \\ Received: 20 September 2018 / Accepted: 10 October 2018 / Published online: 24 October 2018 \\ (c) The Royal College of Ophthalmologists 2018
}

I read with interest the elegant technique of stabilising the globe during intravitreal injections by Wilde et al. [1]. As part of a local NHS innovation pathway, our team has been working on an intravitreal injection guide which allows for similar stabilisation, while also eliminating the need for a drape and speculum.

The Intravitreal Injection Guide (BVI Malosa) consists of a triangular base plate which is curved to follow contour of the eye and has three studs at the corners for stabilisation of the globe. Its apex is placed at the limbus. The base plate is connected to a cylindrical chamber, which in turn is connected to a handle and a lash guard. The lash guard effectively splays lashes away from the site of injection and the injection needle, and the cylindrical chamber allows $7 \mathrm{~mm}$ of a $13 \mathrm{~mm} / 30$ gauge needle to enter the eye. Once base plate is firmly placed on the surface of the eye, the chamber will only allow the injection to be delivered $4 \mathrm{~mm}$ from the limbus, and perpendicular to the sclera. Concerns have been raised about risk of particulate entry into the eye from plastic linings of needle chambers. To negate this, a metal swage tube has been incorporated into the chamber (Fig. 1).

To evaluate the device's performance, 68 patients received an intravitreal injection (with informed consent) using the guide after local Clinical Effectiveness Group approval. $0.5 \%$ Proxymetacaine drops were instilled, followed by $5 \%$ Povidone-Iodine to the lashes/conjunctival sac prior to injection. Follow up was at 4 weeks.

No complications were noted, and the device was found to stabilise the globe well, even in very mobile eyes, without transmitting lid movement. All patients gave positive feedback particularly with regards to elimination of drape and speculum. Results are summarised in Table 1.

Salman Waqar

salman.waqar@nhs.net

1 Royal Eye Infirmary, Derriford Hospital, University Hospitals Plymouth NHS Trust, PL6 8DH, Plymouth, UK

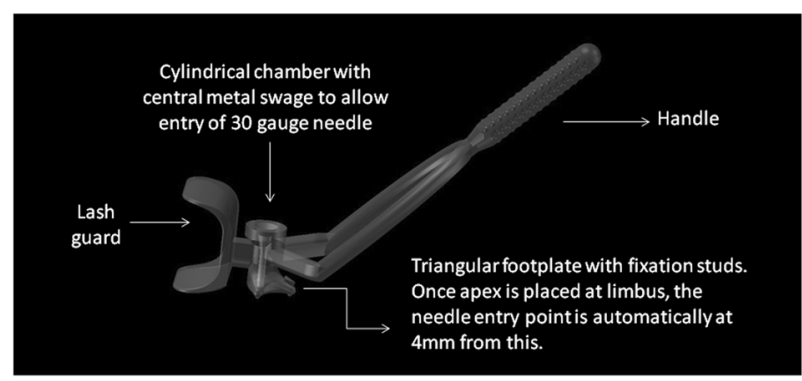

Fig. 1 Design of the intravitreal injection guide

Table 1 Results

\begin{tabular}{|c|c|c|c|c|c|c|}
\hline \multirow{2}{*}{$\begin{array}{l}\text { Age in } \\
\text { years } \\
\text { (Mean) }\end{array}$} & \multirow[t]{2}{*}{ Gender } & \multirow[t]{2}{*}{ Laterality } & \multirow[t]{2}{*}{ Lenticular status } & \multirow{2}{*}{$\begin{array}{l}\text { Complications } \\
\text { (corneal abrasion/ } \\
\text { lens touch/retinal } \\
\text { detachment/ } \\
\text { endophthalmitis) }\end{array}$} & \multicolumn{2}{|c|}{ VA (logMAR) } \\
\hline & & & & & $\begin{array}{l}\text { Pre- } \\
\text { treatment } \\
\text { (Mean) }\end{array}$ & $\begin{array}{l}4 \text { weeks } \\
\text { post } \\
\text { treatment } \\
\text { (Mean) }\end{array}$ \\
\hline 78 & $\begin{array}{l}\text { Male }=48 \% \\
\text { Female }= \\
52 \%\end{array}$ & $\begin{array}{l}\text { Right }= \\
51 \% \\
\text { Left }=49 \%\end{array}$ & $\begin{array}{l}\text { Phakic }=69 \% \\
\text { Pseudophakic }= \\
31 \%\end{array}$ & Nil & 0.33 & 0.32 \\
\hline
\end{tabular}

Medications used were: 55\% Ranibizumab, 43\% Aflibercept, and 2\% Bevacizumab. Indications were: vein occlusion, diabetic retinopathy, or choroidal neovascular membrane

The guide has been developed as part of a unique NHS innovation pathway, meaning revenue generated from its use will be re-directed to improve patient care in our macula service. It is our hope that it will be useful in difficult cases, particularly in the hands of ophthalmic nurse practitioners.

\section{Compliance with ethical standards}

Conflict of interest The authors employing trust (University Hospitals Plymouth NHS Trust) is in a revenue share agreement with BVI Malosa.

\section{References}

1. Wilde C, Awad M, Ross A, Poostchi A, Amoaku W. Optimisation of intravitreal injection technique using a Barraquer speculum with solid flat blade and finger stabilisation. Eye. 2018;32:1413-14. 


\title{
Response to 'Comment on: Optimisation of intravitreal injection technique using a Barraquer speculum with solid flat blade and finger stabilisation'
}

\author{
Craig Wilde ${ }^{1} \cdot$ Mary Awad ${ }^{2} \cdot$ Ali Poostchi $\mathbb{i}^{1} \cdot{\text { Andrew } \text { Ross }^{1} \cdot \text { Winfried M Amoaku (i) }}^{1}$
}

Received: 9 October 2018 / Accepted: 10 October 2018 / Published online: 24 October 2018

(c) The Royal College of Ophthalmologists 2018

We thank the authors for their interest in our technique and congratulate them on the development of their device, which we expect will make a useful contribution to the safe delivery of intravitreal injections (IVT) [1]. Such a device offers distinct safety advantages, particularly with reference to stabilising the globe, determining the point of injection from the limbus, as well as the angle and depth of injection, making the technique user friendly.

We have seen several cases of lens and retinal trauma from IVT over the years, and such a device should hopefully reduce the incidence of these uncommon, but significant problems.

For the majority of patients and trained surgeons the traditional IVT procedure is not difficult or dangerous, and special devices are not required. Reluctance to trial these new products may limit their adoption and widespread use. A comparison against the traditional IVT technique may be required to assess both patient and surgeon preference.

Establishing definite advantages of such IVT devices, including more comfort for patients, increased speed of procedure, or indeed reduced real- world cost, will more likely lead to wider adoption, especially when established instrumentation and techniques like ours are readily available in most eye units.

For now, while devices like the one described here (BVI Malosa), or the InVitrea Injection Assistant (FCI Ophthalmics), have limited uptake across the UK, we hope that people including the non-medical injectors will find our technique for globe stabilisation useful.

\section{Compliance with ethical standards}

Conflict of interest The authors declare that they have no conflict of interest.

\section{References}

1. Waqar S. Comment on: Optimisation of intravitreal injection technique using a Barraquer speculum with solid flat blade and finger stabilization. Eye. 2018. Epub ahead of print. https://doi.org/ 10.1038/s41433-018-0248-3.
Neelakshi Bhagat

bhagatne@njms.rutgers.edu

1 Ophthalmology and Vision Sciences, Division of Clinical Neurosciences, B Floor, EENT Centre, Queen's Medical Centre, University of Nottingham, Nottingham, UK

2 University Hospital, Queen's Medical Centre, Nottingham, UK 


\title{
Optic neuropathy after repair of rhegmatogenous retinal detachment
}

\author{
Jonathan I. Huz ${ }^{1} \cdot$ Tian Xia $^{1} \cdot$ Larry Frohman $^{1} \cdot$ Roger E. Turbin ${ }^{1} \cdot$ Neelakshi Bhagat ${ }^{1}$
}

Received: 11 September 2018 / Accepted: 8 October 2018 / Published online: 1 November 2018

(c) The Royal College of Ophthalmologists 2018

The current report describes the intraoperative clinical setting and peri-operative variables of four patients who developed optic neuropathy after pars plana vitrectomy (PPV) for repair of primary rhegmatogenous retinal detachment (RRD). Baseline history, examination, and intraoperative parameters are displayed in Table 1. All patients underwent RRD repair under general anesthesia. Retrobulbar anesthesia was given through peri-bulbar approach using a blunt cannula at the beginning/end of the surgery.

Mean duration of surgery was $98.5 \mathrm{~min}$ (range 62-135 min). Oxygen saturation was $100 \%$ in all cases. No prior history of glaucoma or optic nerve disorder was elicited in any subject. Three eyes had silicone oil tamponade and one had C3F8. Figure 1 shows intraoperative OPP during the course of surgery. Of note, subject 2 experienced large MAP fluctuations resulting in low OPP $(<30 \mathrm{mmHg}$ for 10 -min and overall $<35 \mathrm{mmHg}$ for $30 \mathrm{~min}$ ). Subject 3 also had low OPP (30 $\mathrm{mmHg}$ for at least $10 \mathrm{~min}$ ). Maximum post-operative IOP noted in follow-up visits, before the diagnosis of optic neuropathy was made, ranged from 15 to $26 \mathrm{mmHg}$. Optic nerve pallor was first noted at an average of 49 days (range 6-74 days) after RRD repair surgery. No eyes had segmental or

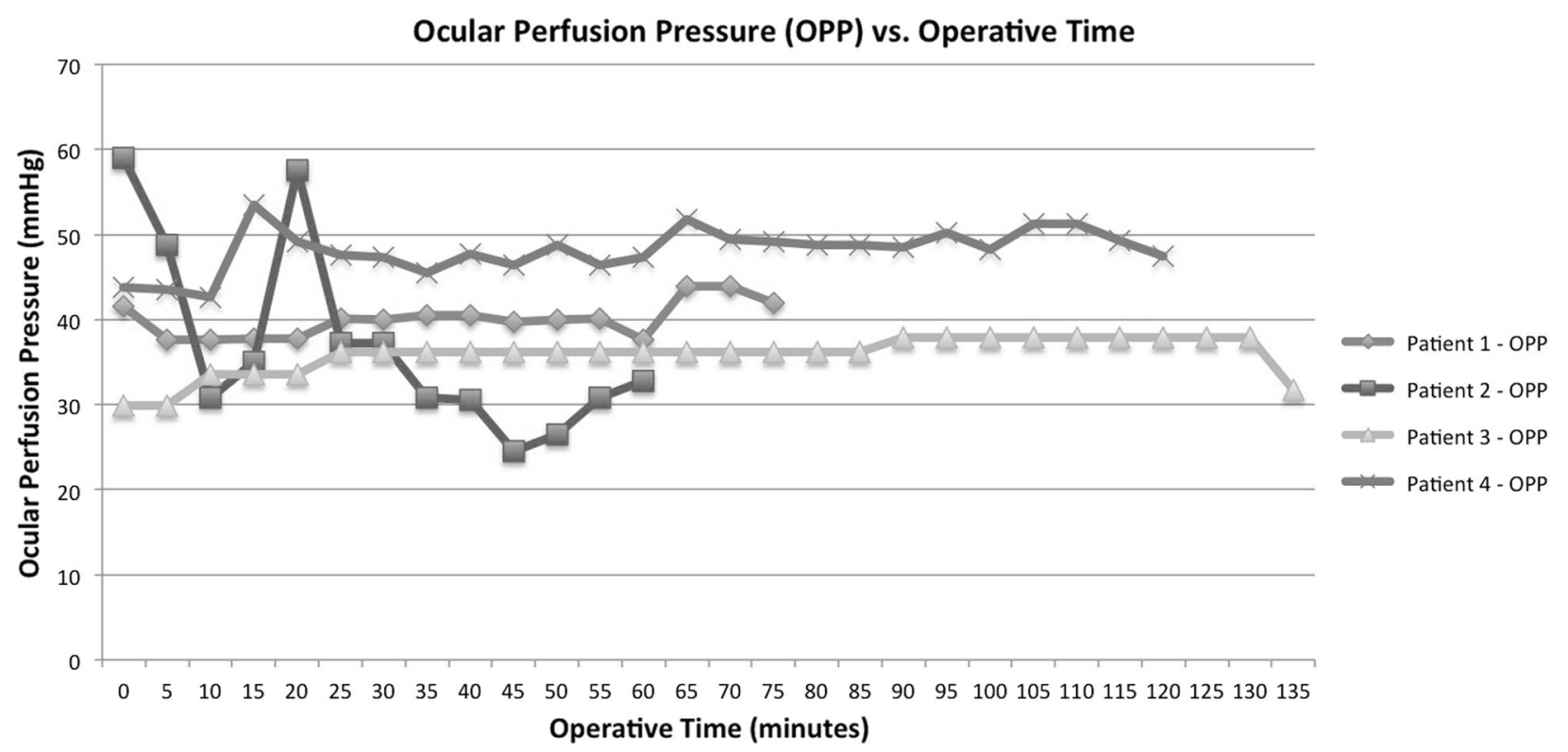

Fig. 1 Ocular perfusion pressure vs. operative time

Neelakshi Bhagat

bhagatne@njms.rutgers.edu

1 Institute of Ophthalmology and Visual Science, Rutgers-New Jersey Medical School, Newark, New Jersey, USA diffuse optic nerve edema, hyperemia or blurring of the disc margins on any post-operative visit. Extensive prothrombotic evaluation revealed a Factor $\mathrm{V}$ Leiden mutation, elevated sedimentation rate, and elevated anti-cardiolipin antibodies in subject 1 , hyperlipidemia in subject 2 , and hyperlipidemia and a slightly elevated $\mathrm{C} 4$ in subject 4 . 


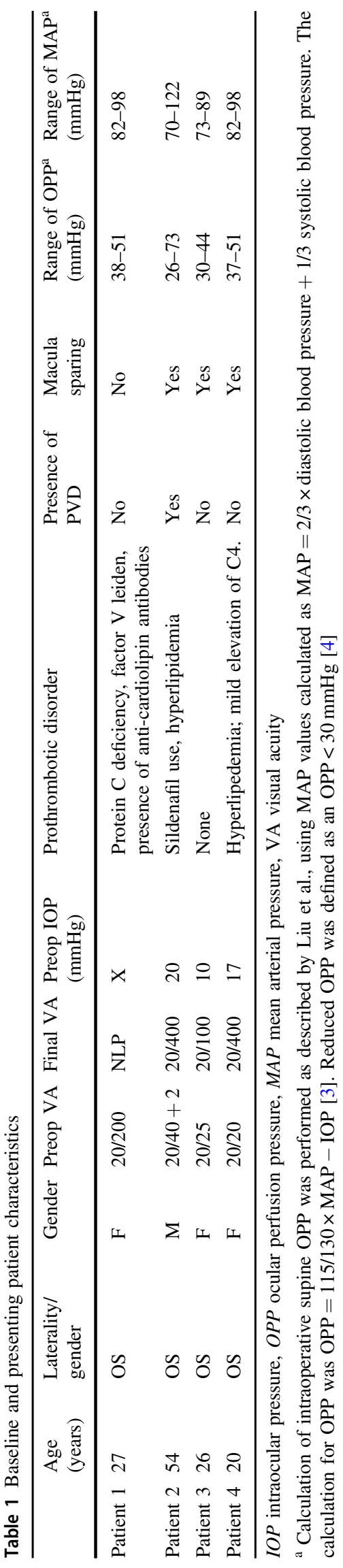

Peri-operative hypo-perfusion of optic nerve is a welldocumented phenomenon that can result in optic neuropathy [1]. Changes in mean blood pressure may have a greater effect on OPP and optic nerve head blood flow than fluctuations in IOP [1]. The optic nerve head can autoregulate its perfusion with fluctuation in blood pressure. Experiments with animal models have described that younger monkeys lose ability to autoregulate optic nerve perfusion once OPP falls below $30 \mathrm{mmHg}$ [1]; no comparable human studies have been performed but similar mechanisms may occur in young adults. In this study, large MAP fluctuations and reduced OPPs $(<30 \mathrm{mmHg})$ were seen in subjects 2 and 3 . Factor V Leiden mutation with elevated anti-cardiolipin antibodies in subject 1 and use of sildenafil [2] in subject 2 (detailed timeline of its use in relation to surgical repair could not be elicited) may have contributed in optic nerve perfusion. In the current study, the average age of patients was 32 years and the duration of operation ranged from 62 to $135 \mathrm{~min}$. Young patients do not have as robust compensatory response to reduced perfusion pressure as older individuals [1]. The longer duration of surgery with relatively prolonged reduced ocular perfusion could have contributed to the development of ischemic optic neuropathy.

Inadvertent optic nerve touch during air-fluid exchange can also cause optic nerve injury, however, there was no record of peripapillary hemorrhage or edema or sectoral pallor of the optic nerve in these eyes. This report highlights the need to be aware of possible effects of low OPP and large MAP variations in young individuals in intraocular procedures.

\section{Compliance with ethical standards}

Conflict of interest The authors declare that they have no conflict of interest.

\section{References}

1. Hayreh SS. Blood flow in the optic nerve head and factors that may influence it. Prog Retin Eye Res. 2001;20:595-624.

2. Karli SZ, Liao SD, Carey AR, Lam BL, Wester ST. Optic neuropathy associated with the use of over-the-counter sexual enhancement supplements. Clin Ophthalmol. 2014;8:2171-5.

3. Liu JH, Gokhale PA, Loving RT, Kripke DF, Weinreb RN. Laboratory assessment of diurnal and nocturnal ocular perfusion pressures in humans. J Ocul Pharmacol Ther. 2003;19:291-7.

4. Bansal AS, Hsu J, Garg SJ, Sivalingam A, Vander JF, Moster M, et al. Optic neuropathy after vitrectomy for retinal detachment: clinical features and analysis of risk factors. Ophthalmology. 2012;119:2364-70. 


\title{
Comment on: 'Association of Chlamydia trachomatis ompA genovar with trachoma phenotypes'
}

\author{
Hugh Taylor ${ }^{1}$
}

Received: 30 April 2018 / Accepted: 1 June 2018 / Published online: 2 November 2018

(c) The Royal College of Ophthalmologists 2018

I was interested to read the paper by Chin et al. [1] that looked at the association of Chlamydia trachomatis ompA genovars and trachoma phenotypes. In their study in Ethiopia, they found that the $93 \mathrm{~B}$ genotypes were somewhat more likely to be associated with more severe disease than the 258A genotypes that they identified. Although their report is brief, they may be interested in studies done in a non-human primate mode that did show that there is not only some variation between different serovars in the clinical response they induce, but also some variation within different strains of serovar [2].

Hugh Taylor

h.taylor@unimelb.edu.au

1 University of Melbourne, Melbourne, Australia
At the time this previous work was done, it was not possible to genotype isolates and so the genetic variation is unknown, although the clinical variation is also quite marked.

\section{Compliance with ethical standards}

Conflict of interest The authors declare that they have no conflict of interest.

\section{References}

1. Chin SA, Alemayehu W, Melese M, et al. Association of Chlamydia trachomatis ompA genovar with trachoma phenotypes. Eye. 2018; 32:1411-1420.

2. Taylor HR. Development of immunity to ocular chlamydial infection. Am J Trop Med Hyg. 1990;42:358-364.

\section{Are patients with ectopia lentis known to cardiology services?}

\author{
P. Maghsoudlou (iD ${ }^{1} \cdot$ T. Khanam ${ }^{1} \cdot$ P. J. Banerjee ${ }^{1,2} \cdot$ A. Chandra ${ }^{1,3}$
}

Received: 15 September 2018 / Accepted: 25 September 2018 / Published online: 5 November 2018

(c) The Royal College of Ophthalmologists 2018

P. Maghsoudlou

p.maghsoudlou@ucl.ac.uk

1 UCL Institute of Ophthalmology, University College London, London EC1V 9EL, UK

2 Department of Ophthalmology, Frimley Park Hospital, Frimley GU16 7UJ, UK

3 Department of Ophthalmology, Southend University Hospital, Southend SSO ORY, UK
Ectopia lentis (EL) is the malposition of the natural lens caused by a defect in the ciliary zonules [1]. The most common cause for EL is Marfan syndrome (MFS) [2]. EL occurs in $~ 70 \%$ of patients with MFS $[3,4]$. Up to $100 \%$ of patients with MFS have an abnormal cardiovascular system predisposing to increased mortality and morbidity [5]. Echocardiography is the mainstay of cardiological assessment for patients with MFS [6]. 
Ophthalmologists are well aware of the ocular risks of EL and routinely survey for these. However, ensuring cardiovascular assessments may be less-regularly documented. Herein we audit documentation of whether patients with EL are known to cardiologists, geneticists or physicians for their systemic cardiovascular risks.

Eligible patients were identified from the database of a tertiary ophthalmic centre: Moorfields Eye Hospital, London. A database search between 1 January 1959 and 31 December 2011 was performed. The inclusion criteria were all referrals for EL or for syndromes associated with EL. Patients were excluded if the EL diagnosis was not confirmed, or if patients were subsequently seen elsewhere.

The standard of the audit was that all patients should have documentation that the patient is under cardiovascular review.

In all, 191 patients fulfilled the inclusion criteria. Ninetyseven patients $(51 \%)$ had documentation that they were under cardiovascular review. Of these, 38 (20\%) were documented to be known as having cardiovascular issues, while 59 patients (31\%) did not. A total of 94 patients (49\%) had no documentation regarding cardiovascular problems.

Our findings describe the lack of documentation ensuring cardiovascular review for patients with EL. Ophthalmologists are well aware that the most common cause of EL is MFS and associated cardiovascular risks. It is important for patient safety that these patients are known to cardiology or medical services. Ophthalmologists first see $\sim 40 \%$ of patients with MFS [7]. It is critical therefore to ensure that patients with EL are under the care of appropriate physicians. There are currently no guidelines on referral pathways for patients who present to ophthalmologists with EL, suggesting the need to review investigation and management of this cohort.

\section{Compliance with ethical standards}

Conflict of interest The authors declare that they have no conflict of interest.

\section{References}

1. Stone JH. Ectopia lentis, cardiology, and the sign of the tremulous iris. Am Heart J. 1966;72:466-8.

2. Chandra A, Charteris D. Molecular pathogenesis and management strategies of ectopia lentis. Eye 2014;28:162-8.

3. Marsalese DL, Moodie DS, Vacante M, Lytle BW, Gill CC, Sterba $\mathrm{R}$, et al. Marfan's syndrome: natural history and long-term followup of cardiovascular involvement. J Am Coll Cardiol. 1989;14: 422-8-31.

4. Rubin S, Nelson L. Ocular manifestations of autosomal dominant systemic conditions. In: Tasman W, Jaegar E, editors. Duane's clinical ophthalmology. 2nd ed. Lippincott Williams and Wilkins; Philadelphia 2006.

5. Graham Stuart A, Williams A. Marfan's syndrome and the heart. Arch Dis Child. 2007;92:351-6.

6. Child AH. Diagnosis and management (Summary). In: Diagnosis and management of Marfan Syndrome. (ed.) Child, Anne H. London: Springer; 2016. p. 3-11.

7. Strider D, Moore T, Guarini J, Fallin B, Ivey J, Kron I. Marfan's syndrome: a family affair. J Vasc Nurs. 1996;14:91-98.

\title{
Periocular basal cell carcinoma in under 40's - Is more aggressive treatment warranted?
}

\author{
Edward Saxby $^{1} \cdot$ Mark Wright $^{1} \cdot$ Rhys Davies $^{1}$
}

Received: 15 November 2018 / Accepted: 15 November 2018 / Published online: 5 December 2018

(c) The Royal College of Ophthalmologists 2018

Edward Saxby

e_saxby@hotmail.com

1 Princess Alexandra Eye Pavilion, Chalmers Street, Edinburgh EH3 9HA NHS Lothian, UK
Basal cell carcinoma (BCC) is the most common form of skin cancer. It is slow growing and locally invasive. Risk factors include ultraviolet light exposure, increasing age, fair skin, immunosuppresion and familial conditions e.g. Gorlins Syndrome [1]. BCCs are commonly diagnosed in elderly populations but are still rarely diagnosed in youth [2]. We investigated the incidence, treatment and outcome 
Table 1 Characteristics of BCCs in the under 40's

\begin{tabular}{ll}
\hline Age (mean) & 33.8 years ${ }^{(+/-4.1 \mathrm{SD})}$ \\
\hline Sex & 6 Males, 7 Females \\
Pathology & 8 Nodular, 4 Morphoeic, 1 \\
& $\begin{array}{l}\text { Basisquamous } \\
\text { Time from onset of signs to }\end{array}$ \\
treatment (mean) & \\
Recurrence & 3 patients \\
Time to recurrence (mean) & 2.3 years ${ }^{(+/-0.6 \mathrm{SD})}$ \\
\end{tabular}

of patients under 40 years of age with a histologically confirmed diagnosis of a periocular BCC.

A retrospective analysis of all patients that attended a 'tumour clinic' at the Edinburgh Princess Alexandra Eye Pavilion, over a 17-year period, was performed. Cases were identified from pathology diaries in which all patients that undergo a biopsy for suspected periocular malignancy are logged. This allowed us to identify all patients under the age of 40 that had a histologically confirmed BCC. ${ }^{1}$

Over the 17-year period 1068 biopsies were performed. Pathology results confirmed 720 of the biopsies were BCCs. We found 13 BCCs present in the under 40's population with a mean length of follow up of 31 months ${ }^{(+/-21 \mathrm{SD})}$ (Table 1).

We have shown a prevalence of periocular BCC's in our under 40's population of $1.8 \%$ which is in keeping with national data showing a BCC prevalence of $1.2 \%$ in patients aged 15-35 years [3].

Recurrence was defined as histologically confirmed $\mathrm{BCC}$, arising at the site of previous surgery. A recurrence rate of $23.1 \%$ in our 'under 40 's' population is 12 times greater than our overall audited recurrence rate of $1.9 \%$, with 17 year follow up, and the national average of $<2 \%$, with a five year follow up [2]. None of the recurrence cases had any underlying risk factors.
Margins of $2 \mathrm{~mm}$ are our standard practice. In one case of recurrent tumour, to preserve the lid margin, the surgical excision was less than $2 \mathrm{~mm}$ superiorly. Two of the three cases of recurrent tumour were noted to be morphoeic and in both cases the tumours were completely excised according to histology. Recurrence following histologically confirmed complete excision occurs in $1.3 \%$ of cases [3]. Our findings highlight the need for ongoing follow up irrespective of the histology report.

The time from onset of signs/symptoms to treatment was 2.7 years $^{(+/-1.1 \mathrm{SD})}$ in our study population. We believe this demonstrates a significant diagnostic delay.

BCCs in under 40's are rare; however the recurrence rate in this population is 12 times higher than our overall audited recurrence rate. This may reflect a higher proportion of morphoeic tumours, associated with an increased recurrence rate, or an intrinsically more aggressive disease. Given the significantly higher recurrence rate for patients under 40 , we would recommend larger excision margins or excision with Moh's micrographic technique and a prolonged follow up period.

\section{Compliance with ethical standards}

Conflict of interest The authors declare that they have no conflict of interest.

\section{References}

1. Foundation TBS. Basal Cell Carcinoma http://www. britishskinfoundation.org.uk/SkinInformation/AtoZofSkindisease/ BasalCellCarcinoma.aspx.

2. Pandeya NOC, Whiteman D. The incidence and multiplicity rates of keratinocyte cancers in Australia. Med J Aust. 2017;207:339-43.

3. Basal NC. Cell Carcinoma in young Adults. Br J Dermatol. 1992;127:26-9.

\footnotetext{
1 This project was orally presented at the British Oculoplastics Society Meeting in Dublin June 2018.
} 